\title{
AN IMPROVED DISCHARGE TECHNIQUE FOR EXCIMER LASERS
}

\author{
J.W. GERRITSEN, A.L. KEET ${ }^{1}$, G.J. ERNST and W.J. WITTEMAN \\ University of Twente, Dept. of Applied Physics, P.O. Box 217, 7500 AE Enschede, The Netherlands
}

Received 15 November 1989; revised manuscript received 5 February 1990

\begin{abstract}
The further development of discharge excimer lasers depends upon a better degree of control over the discharge stability. A problem is the large difference between the breakdown and steady-state voltage which requires a time dependent impedance of the power circuit. Further the large attachment rates of halogens like $\mathrm{HCl}$, causing electric field disturbances require a short rise time of the applied current pulse. A large effort has been expended towards this goal by researchers since the early development of discharge excimer lasers.
\end{abstract}

A breakthrough in this development was obtained by the introduction of the so-called prepulse-mainpulse technique in which the prepulse is used for the avalanche ionization process during the breakdown phase whereas the main pulse is applied under quasisteady state conditions [1-3]. Although this technique was introduced by using a rail gap to separate the circuits further improvements were obtained with passive magnetic switches [2,3]. There is a choice of two polarities for the prepulse circuit with either a current reversal in the magnetic inductor or a current reversal through the discharge. In the first case there is a delay because of the saturation process in the switch and in the second case a larger magnetic core area is required which gives a larger saturated inductance. In both cases the main pulse is hampered by a rise time which is too long with respect to the electron attachment rate and the streamer formation time causing a decrease of discharge quality.

The present contribution describes an improvement of the excimer laser discharge technology. It allows for a much better adaptation of the circuits to the discharge with minimum delay between prepulse and main pulse currents. Up till now an efficiency of $5 \%$ has been obtained for the conversion of the total electrical stored energy into optical radiation. Furthermore the improved discharge stability shows that

1 Holec, Innovation and Technology, P.O. Box 23, 7550 AA Hengelo, The Netherlands. for high energy deposition the optical pulse does not terminate early before the end of the current pulse. For a discharge current of about $150 \mathrm{~A} / \mathrm{cm}^{2}$ optical pulses of about $200 \mathrm{~ns}$ were found.

The scheme of the electric circuit is shown in fig. 1. The PFN and the peaking capacitor $\mathrm{C}_{3}$ are charged within a few microseconds to twice the steady state voltage $\left(V_{\text {ss }}\right)$ of the $\mathrm{XeCl}$ excimer laser. The saturable inductor $\mathrm{L}_{4}$ is the magnetic switch of the PFN to the laser. In the prepulse circuit $\mathrm{C}_{2}$ is about equal to $\mathrm{C}_{3}$ and charged to $-4 \mathrm{~V}_{\mathrm{ss}}$ with the indicated polarity. Switching $S$ in approximately $1 \mu$ s after loading the PFN it is seen that there is a ringing circuit between the $C_{2}$ and $C_{3}$ with a high impedance of $L_{4}$. As a result the voltage of $\mathrm{C}_{3}$ changes to $-2 \mathrm{~V}_{\mathrm{ss}}$. During this period $\mathrm{L}_{4}$ is saturated so that the PFN (at $2 \mathrm{~V}_{\mathrm{ss}}$ ) is directly connected to the peaking capacitor. Since $C_{3}$ was charged to $-2 V_{s s}$ it will now in principle be resonantly charged to $6 V_{s s}$ in a very short time depending on the saturated inductance of $L_{4}$.

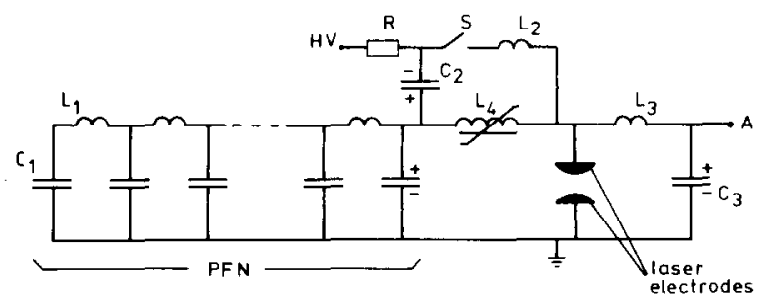

Fig.1. Diagram of the discharge circuit. 


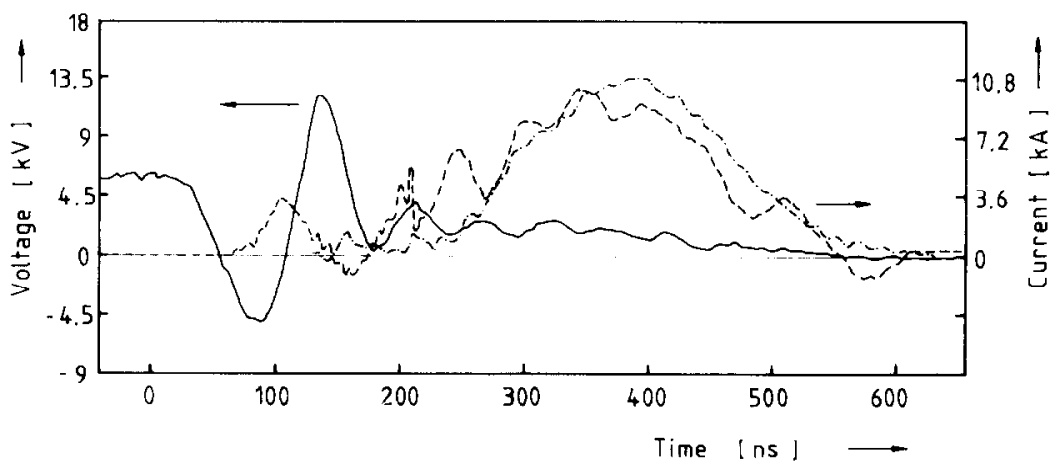

Fig. 2. Waveforms of the voltage (solid line), current (broken line) and output pulse (dashed line) of the described XeCl laser.

This occurs shortly after the X-ray preionization pulse. However even before reaching $6 \mathrm{~V}_{\mathrm{ss}}$ this peaking capacitor acts with the laser electrodes as the prepulse circuit for the avalanche ionization process. Then, by reaching the characteristic impedance of the PFN, the main pulse will follow immediately because the charging current of the peaking capacity and the discharge current have the same direction. Thus there is no current reversal either in the discharge or in the magnetic inductor.

This scheme has becn successfully applicd to our $\mathrm{X}$-ray preionized $\mathrm{XeCl}$ laser as described in ref. [4]. The PFN contains ceramic capacitors having a total capacity of $300 \mathrm{nF}$, a characteristic impedance of 0.3 $\Omega$ and a double transit time of $160 \mathrm{~ns}$. The peaking capacitance is formed by 14 parallel capacitors of 460 pF each. The saturable inductor $\mathrm{L}_{4}$ consists of two parallel race tracks of SEI type K4 ferrite blocks and is biased externally. The laser has a discharge length of $60 \mathrm{~cm}$ and an electrode gap of $1.5 \mathrm{~cm}$. The selfinductance between the PFN and the laserhead is about $30 \mathrm{nH}$ when inductor $\mathrm{L}_{4}$ is saturated. The cavity consists of a $5 \mathrm{~m}$ radius end mirror and a $70 \%$ reflectivity output mirror separated at $130 \mathrm{~cm}$. The filling gas mixture contains $2 \mathrm{mbar} \mathrm{HCl}, 20$ mbar Xe and 4 bar Ne. With a calibrated Gentec ED500 energy meter an output energy of $0.28 \mathrm{~J}$ has been obtained. The PFN is charged to $5.5 \mathrm{kV}(4.5 \mathrm{~J})$ and $\mathrm{C}_{2}$ to $17.4 \mathrm{kV}(1.1 \mathrm{~J})$ so that the efficiency is $5 \%$. The wave forms of voltage between the electrodes, discharge current and output power of this laser are shown in fig. 2. A more detailed description of alternative circuits based on the same principle will be published elsewhere [5].

This work was supported by the Dutch Foundation for Fundamental Research on Matter (FOM).

\section{References}

[1] W.H.Long, M.J. Plummer and E.A. Stappaerts, Appl. Phys. Lett. 43 (1983) 735.

[2] R.S. Taylor and K.E. Leopold, Appl. Phys. Lett. 46 (1985) 335.

[3] C.H. Fisher, M.J. Kushner, T.E. De Hart, J.P. McDaniel, R.A. Petr and J.J. Ewing, Appl.Phys. Lett. 48 (1986) 1574

[4] J.W. Gerritsen and G.J. Ernst, Appl. Phys. B 46 (1988) 141.

[5] J.W. Gerritsen, A.L. Keet, G.J. Ernst and W.J. Witteman, J. Applied Physics, to be published. 